\title{
Prevention of infection in operating theatres
}

\author{
R. A. SHOOTER and R. E. O. WILLIAMS \\ From the Department of Bacteriology, St. Bartholomew's Hospital, London, and the Wright-Fleming Institute, \\ St. Mary's Hospital Medical School, London
}

Sepsis arising at the time of operation has proved easier to understand than some other forms of crossinfection. Conditions in the operating theatre are normally straightforward: usually only one patient is exposed, and the surgical team consists of a restricted number of doctors and nurses, who by tradition follow a strict routine. In this paper we have summarized, in a somewhat dogmatic form, our present views on operating theatre design and practice insofar as they affect the prevention of infection. Staphylococcal infection, clostridial infection, and infection of the urinary tract with miscellaneous bacteria will be our chief topics, with particular emphasis on those features that have been clearly shown to be effective in prevention. It is, of course, likely that with further experience the emphasis will change and some of the preventive measures that, for lack of precise facts, we have barely mentioned may later assume greater prominence.

\section{STAPHYLOCOCCAL WOUND SEPSIS}

RECORDS The only reliable method by which the surgeon can find out how many of his wounds heal without sepsis is to arrange for the keeping of records specifically for the purpose; impressions are often quite misleading. How and where the records are kept is less important than acceptance of the principle that they are worth keeping. An attempt should be made to distinguish infection arising at the time of operation from infection originating subsequently. In general, pus present at the first dressing, pus deep in the wound, and fever early after the operation suggest infection in the operating theatre, although the distinction may not be an easy one to make and may not be possible at all. Records based solely on laboratory results are liable to be misleading because the indications for sending specimens to the laboratory will vary with circumstances, and because clinical signs of disease are more important than positive bacteriological cultures. The responsibility for keeping the sepsis record should be carried by the surgeon in charge of the patient, or by a member of his team.
SEPSIS ARISING FROM SURGEONS WITH SEPTIC LESIONS While it is true that there are innumerable instances of surgeons operating while suffering from furunculosis or other septic lesions with no apparent harm, it is also true that this practice has led to catastrophe. McDonald and Timbury (1957) and Mitchell, Timbury, Pettigrew, and Hutchinson (1959), for instance, both reported outbreaks of sepsis from this cause and unless there is some absolutely compelling reason surgeons with active sepsis should not operate.

SEPSIS ARISING FROM CARRIERS The evidence that a healthy staphylococcal carrier in the surgical team can infect a wound at the time of operation is of two sorts. In a pioneer paper Devenish and Miles (1939) described an outbreak of post-operative wound sepsis in which nearly all the infections occurred in patients operated on by one of the four surgeons in the team. The surgeon concerned was a healthy nose and hand carrier of Staph. aureus, and Devenish and Miles thought that the most probable route of infection was through the permeable sleeves of his gown or through glove punctures. Phage typing has confirmed circumstantial incrimination of carriers in several more recent studies. Blowers, Mason, Wallace, and Walton (1955) reported an outbreak of sepsis due to Staph. aureus of phage type 79 which was clearly traced to a surgical assistant. A surgical assistant was also implicated in the outbreak reported by Shooter, Griffiths, Cook, and Williams (1957); of 45 operations in which he took part no less than 24 resulted in sepsis. The staphylococcus responsible was of phage-type 47/53/75/77. In America, Browne, Ryan, Glassow, Martin, and Shouldice (1959) traced infection to a surgeon carrying a staphylococcus of type 81 .

The carrier apparently need not necessarily be one of the surgical team who has a hand in the wound in order to cause infection. Penikett, Knox, and Liddell (1958) described infection coming from a scrubbed nurse handling suture material, and Sompolinsky, Hermann, Oeding, and Rippon 1957) thought that nurses performing unscrubbed duties in the theatre were responsible for a number of cases of infection. 
Approximately a third of gloves used by surgeons are perforated during the course of an operation and the surprising thing is perhaps that sepsis from staphylococci carried on the surgeons' hands is as infrequent as it appears to be. Presumably, to produce a significant number of cases a surgeon has to have moist hands on which he carries a dangerous staphylococcus. As routine bacteriological examination of all surgeons' hands is impracticable, an individual with these characteristics may cause considerable damage before being detected, especially if adequate records are not kept. Normal scrubbing up with soap and water will not remove all staphylococci from the skin of the true hand carrier. In most cases the regular use of hexachlorophane, either as a fluid preparation or in soap, will abolish staphylococcal carriage or reduce it to a negligible level, and because there is no other single way of guarding against the dangerous hand carrier, the routine use of hexachlorophane appears to be justified.

SEPSIS FROM AIRBORNE STAPHYLOCOCCI Despite the work of Wells and his colleagues in America (Wells, 1934; Wells and Wells, 1936; Hart, $1938 \mathrm{a}, \mathrm{b})$, the suggestion that wounds might be infected at operation from the air was not readily accepted in Britain. Bacteriological support came first. Bourdillon and Colebrook (1946) and Bourdillon, McFarlan, and Thomas (1948) examined the bacterial content of air in ward dressing rooms and operating theatres. They showed that in unventilated or poorly ventilated rooms the air might contain many bacteria. These might be derived from reservoirs such as infected dressings or carriers inside the room, or might be sucked into the room by faulty ventilation. When exhaust ventilation was replaced by plenum or positive-pressure ventilation bacterial contamination of the air was strikingly reduced. These views were accepted in theory but for several reasons were usually ignored in practice. One reason was that penicillin had become generally available and, with most staphylococci sensitive, provided an apparent solution to the problems of hospital infection. The solution proved to be only a temporary one. The steady increase in the numbers of penicillin-resistant staphylococci led to renewed interest in operating theatre ventilation, and by this time phage typing was available to assist investigation.

The observation that theatres ventilated with exhaust fans had high air counts was confirmed, but some investigators were able to go further and show that replacement of the original ventilating plant by one which ventilated the theatre under positive pressure not only led to reduced counts of airborne bacteria, but also produced a sharp fall in post-operative wound infection (Blowers et al. 1955; Shooter, Taylor, Ellis, and Ross, 1956).

In an operating theatre. the ventilation has to perform a number of different tasks. It must provide comfortable working conditions; it has to $\frac{\bar{s}}{7}$ remove anaesthetic gases, and it has to supply $\mathbb{\mathscr { Q }}$ bacteriologically pure air in which the patients' tissues के can be safely exposed. These tasks fortunately do not conflict. Published results suggest that the most serious ventilation defect in an operating theatre is $\overrightarrow{\vec{\omega}}$ the suction of air into the theatre from adjacent $\stackrel{\omega}{\rightarrow}$ wards. It is in wards that resistant staphylococci 용 are bred and ward air may be laden with them. In Britain suction ventilation is still all too com- $\stackrel{\vec{t}}{-}$ mon. In many older theatres a single extract fan of is installed to remove steam. Some theatres have no artificial ventilation but even in these, because the theatre is usually warmer than ad- $\vec{c}$ joining corridors, thermal currents may transfer hospital air to the theatre. And even in new operating theatres the ventilation plant, which on the drawing board was designed to provide positive $\vec{\varphi}$

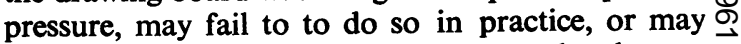
fail to ensure that air flows out from the theatre, both at the bottom and at the tops of doorways, under all circumstances.

There is no difficulty in deciding whether air is being sucked into a theatre. With a plume of smoke $\frac{\mathscr{Q}}{\Phi}$ from a swab dipped in titanium tetrachloride, $\stackrel{\varrho}{\Rightarrow}$ air movements can be watched. All new theatres $\overrightarrow{\overrightarrow{0}}$ should be tested before they are accepted from the 3 builders. One reason for failure of pressurization has been an attempt on the part of the designer to provide a balanced air input and exhaust; during use the volume of input tends to fall below that of the exhaust, and air is sucked into the theatre in a way not envisaged in the design. To provide reliable positive pressure requires the supply of approximately 12 to 15 changes of air an hour (usually응 equivalent to about $1,000 \mathrm{cu}$. $\mathrm{ft}$. per min.). If more than about one third to one half of this air is takeno away by an extraction fan, it is unlikely that satisfactory positive pressure will be present. Althougho it is rare that doors fit so tightly that air will not ben able to escape around them, it is probably best toN provide planned air outlets with weighted flap ${ }_{\sigma}^{\omega}$ valves arranged to open only when there is a pressure difference of $0 \cdot 1-0 \cdot 2$ in. water gauge between the operating room and the space outside.

Ideally the incoming air should be filtered and humidified, but where for financial reasons this is not possible, or in an interim period while waiting for new building, the risks of suction ventilation may? far exceed those of using unfiltered air and it is stilp desirable to replace existing exhaust fans with inpuk 
fans. The size of the risk involved in suction ventilation will plainly depend on the situation of the theatre. If infection were the only consideration, theatres would probably be best built in separate blocks away from wards; temporary hospitals consisting of separate huts would seem to offer a situation in which the validity of this idea could be tested. Conversely, the risk of airborne infection is greatest with theatres on the top floor of high buildings.

In a new theatre, or a reconstruction of an old one, the incoming air should be humidified for comfort and safety and supplied through a filter which will retain $95 \%$ of particles down to 5 microns in diameter. Filters of this type will impose no excessive mechanical problems.

Staphylococci may be liberated within the theatre either from the patient or his bedding, or from the staff. Where this can be avoided, it should be, and no patient should come to the theatre with bedding which has been in use in the ward. Carriers present a more difficult problem, as they may shed staphylococci while changing their clothes, while washing, or even when dressed in theatre uniform. Changing and scrubbing-up rooms should be separated from the operating theatre, and the theatre staff should be instructed to plan their work in such a way as to avoid unnecessary movements. However, the surgeon's work is not always easy and it may call for sudden decisions which have to be made in moments of anxiety; over-emphasis on the aseptic precautions may not be in the best interests of the patient.

A further safeguard is provided by the ventilation. At an air-change rate of 12 per hour the concentration of airborne bacteria will on average be only about one third to one half of the concentration that might be found with rates of 2 per hour. This is a further justification for requiring good levels of ventilation, though it is not possible to provide a quantitative estimate of the improvement in infection rates to be expected from any particular improvement in the ventilation rates. There is still some controversy as to the best method of distributing the ventilating air within the theatre but satisfactory results seem to be attainable in practice either by methods designed to give turbulent mixing, or by those giving downward displacement ventilation.

SEPSIS ARISING FROM PATIENT'S OWN ORGANISMS Patients may develop sepsis due to staphylococci which they carried before operation (Williams, Jevons, Shooter, Hunter, Girling, Griffiths, and Taylor, 1959; Weinstein, 1959). Most cases of selfinfection probably arise in the ward but the possibility is mentioned here to emphasize particularly the importance of proper skin sterilization.

SEPSIS FROM UNSTERILE INSTRUMENTS AND DRESSINGS Failure to sterilize equipment is a most important cause of clostridial infection and of urinary infection, and will be referred to again. Staphylococci are easily killed by heat, and given satisfactory working conditions and good theatre discipline, it may be doubted if failure to sterilize equipment is more than a very exceptional cause of theatre staphylococcal infection.

In summary, the amount of sepsis originating in the operating theatre is dependent in the first place on the care with which the surgical team carry out aseptic techniques. The breaks in aseptic technique are not always easily recognized by the surgeon. His equipment may, but very rarely, contain staphylococci capable of initiating infection. He or a member of his team may become a hand carrier of an epidemic strain of Staph. aureus, or may suffer from actual staphylococcal infection. The patient's own staphylococcus may survive on the skin around the wound or may be transferred to it from unsterilized skin by careless use of towels. And if the ventilation is faulty the most meticulous operative technique may not be enough to prevent sepsis. When confronted with an outbreak of post-operative sepsis it may be worth considering these factors. It may prove that the cause of the outbreak was a specific and recognizable one, rather than, as suggested by the not unusual generalization, that surgeons nowadays brought up with antibiotics are less careful than their predecessors.

\section{CLOSTRIDIAL INFECTIONS}

TETANUS Few wounds provide the conditions necessary for clostridia to grow, and this is fortunate, as spores of Clostridium tetani are frequently present in hospital dust and may be found in or on many objects (Lowbury and Lilly, 1958a; Report of the Public Health Laboratory Service, 1959). There is very little evidence that tetanus has resulted from direct airborne contamination of wounds: in nearly all reported cases articles contaminated with tetanus spores have come in contact with the wound. Some substances are by their nature and mode of manufacture particularly liable to contamination. Catgut, cellulose wadding, cottonwool, plaster of Paris bandages, and dusting powder have all been incriminated as causes of clinical tetanus, while catgut and dusting powder have been held responsible for tetanus arising at the time of operation. 
Catgut is now effectively sterilized during preparation; proper sterilization will also ensure that, even if present, tetanus spores are killed in the other substances. Unsterile and potentially infected articles such as unbleached cottonwool and cardboard should never be brought into the operation theatre.

Patients about to undergo operation on old sites of injury which may still harbour tetanus spores should be protected by immunization. Passive immunization will protect for a time, but as there is rarely any urgency in these cases active immunization is nearly always feasible and much to be preferred.

Tetanus is only rarely seen in this country as a hospital infection but the outcome is so often fatal that a determined and sustained effort must be made to prevent it.

GAS GANGRENE Spores of clostridia capable of causing gas gangrene are even more widely spread in hospital than those of $\mathrm{Cl}$. tetani (Lowbury and Lilly, 1958b; Noble, 1961). Many pathologists have had the disturbing experience of isolating Cl. welchii from the floors or walls of operating theatres, while clostridia contaminate approximately a third of war wounds and peace-time burns (MacLennan, 1943, 1944; Lowbury and Lilly, 1958b) and it is not unusual to find $\mathrm{Cl}$. welchii in post-operative wounds. Despite this, gas gangrene is uncommon. Unlike tetanus, the responsible clostridia have in most cases probably come from the patient himself. This is particularly likely to be so in amputations through the upper part of the thigh.

Prevention of gas gangrene lies again partly in efficient sterilization of articles brought in contact with the patient's wound. But, as there is no form of pre-operative skin sterilization which can be relied on to kill spores, and as the skin within some distance of the anus will probably be contaminated with spores of $\mathrm{Cl}$. welchii, high thigh amputation is one of the few operations in which the routine use of large doses of penicillin is justified.

\section{URINARY INFECTION FROM UNSTERILE INSTRUMENTS}

Urological surgery is the one field in which proper sterilization of the surgeons' instruments is difficult, and has often been seriously deficient. Some cystoscopes and similar instruments are too delicate to stand sterilization by autoclaving or even by immersion in boiling water. Indeed, it may not be possible, strictly speaking, to "sterilize" such an instrument, but it should be possible to rid it of bacteria pathogenic from the urinary tract. There are now two simple ways of doing this, and of doing it sufficiently quickly to permit of the instrument being used repeatedly throughout an operating session. Francis (1959) described a "pasteurizer" which was simply a water bath thermostatically controlled at $70-75^{\circ} \mathrm{C}$. Immersion in this bath for 10 minutes is sufficient to kill vegetative bacteria, and in practice has not been found to damage any but the most delicate instruments.

If a pasteurizer is neither available nor desired, chemical disinfection properly used will kill all vegetative bacteria, other than tubercle bacilli. Methods of chemical disinfection are discussed in the article in this journal by Dr. W. A. Gillespie (page 26).

It is to be hoped that manufacturers will soon produce cystoscopes and their attachments which can be sterilized in an instrument autoclave, or at least in boiling water. In the meanwhile, however, either chemical disinfection or "pasteurization" seems a reasonable compromise. The pasteurizer $\overrightarrow{\mathscr{Q}}$ can also be used for other heat-sensitive equipment $\stackrel{\circ}{\rightarrow}$ like anaesthetic face masks and tubing.

\section{REFERENCES}

Blowers, R., Mason, G. A., Wallace, K. R., and Walton, M. (1955). 을 Lancet, 2, 786.

Bourdillon, R. B., and Colebrook, L. (1946). Ibid., 1, 561, 601.

-, McFarlan, A. M., and Thomas, J. C. (1948). Spec. Rep. Ser. med. Res. Coun. (Lond.) No. 262, p. 241.

Browne, A. F., Ryan, E. A., Glassow, F. J., Martin, Caroline J., and Shouldice, E. E. (1959). J. Amer. med. Ass., 170, 1274

Devenish, E. A., and Miles, A. A. (1939). Lancet, 1, 1088.

Francis, A. E. (1959). Proc. roy. Soc. Med., 52, 998.

Hart, D. (1938a). Arch. Surg. (Chicago), 37, 521.

- (1938b). Ibid., 37, 956.

Lowbury, E. J. L., and Lilly, H. A. (1958a). Brit. med. J., 2, 1334.

- (1958b). J. Hyg. (Lond.), 56, 169.

MacLennan, J. D. (1943). Lancet, 1, 582.

(1944). Ibid., 1, 203.

McDonald, S., and Timbury, M. C. (1957). Ibid., 2, 863.

Mitchell, A. A. B., Timbury, M. C., Pettigrew, J. B., and Hutchinson, J. G. P. (1959). Ibid., 2, 503.

Noble, W. C. (1961). J. Path. Bact. In press.

Penikett, E. J. K., Knox, R., and Liddell, J. (1958). Brit. med. J., 1, 812 .

Report of the Public Health Laboratory Service (1959). Ibid., 1,1150 .

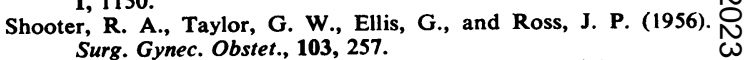

—-, Griffiths, J. D., Cook, J., and Williams, R. E. O. (1957). Brit. med. J., 1, 433.

Sompolinsky, D., Hermann, Z., Oeding, P., and Rippon, Joan E. (1957). J. infect. Dis., 100, 1.

Weinstein, H. J. (1959). New Engl. J. Med., 260, 1303.

Wells, W. F. (1934). Amer. J. Hyg., 20, 611.

and Wells, M. W. (1936). J. Amer. med. Ass., 107, 1698,

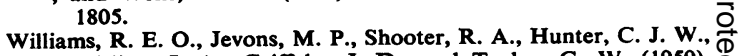
Girling, J. A., Griffiths, J. D., and Taylor, G. W. (1959). 尺 Brit. med. J., 2, 658. 